\title{
Metamorfosis en la energía mítica: de la libido freudiana a la libido electrónica y digital
}

\section{Mythical Energy Metamorphosis: from the Freudian Libido to the Electronic and Digital Libido}

\author{
Vicente Alemany \\ Universidad Rey Juan Carlos. \\ vicente.alemany@urjc.es \\ JAIME REPOLLÉS-LLAURADÓ \\ U-tad University of Technology and Design. \\ jaime.repolles@live.u-tad.com
}

Recibido: 22 de abril de 2015

Aprobado: 3 de julio de 2015

\begin{abstract}
Resumen
La historia de la mitología puede ser narrada como la crónica de las sucesivas metamorfosis de las fuentes de energía mítica y sus desplazamientos metafóricos de sentido. La modernidad se distingue por haber descubierto un manantial inédito de energía mítica, la libido freudiana. Desde su despertar surrealista, donde se creía inagotable, hasta su empleo por parte de los dispositivos pulsionales de Internet, el imaginario de la libido freudiana está sufriendo una mutación como libido digital: una crisis energética que supone una lectura renovada del imaginario edípico (crisis de la diacronía) y un estudio de sus más recientes rituales electrónicos (crisis de la sincronía) en la era de Internet.

Palabras clave: Libido freudiana, imaginario edípico, libido digital, imaginario electrónico.
\end{abstract}

Alemany, V., Repollés-Llauradó, J. (2016): Metamorfosis en la energía mítica: de la libido freudiana a la libido electrónica y digital. Arte, Individuo y Sociedad, 28(3) 443-457

\begin{abstract}
The history of mythology can be framed as the unearthing of successive metamorphical sources of mythological energy and their metaphorical displacements of sense. Modernity is distinguished for having uncovered a new and hitherto unknown stream of mythological energy, the Freudian libido. From its Surrealistic awakening, during which it was believed to be inexhaustible, to its current drive into the world of Internet devices, this Freudian libido is undergoing a transformation into a "digital libido": a crisis of energy that implies a renewed reading of Eodipic imaginary (crisis of the diachronic approach) and a study of its more recent electronic rituals (crisis of the synchronic approach) in the Internet era. Keywords: Freudian libido, the Eodipic imaginary, Digital libido, the Electronic imaginary.

Sumario: 1. La transformación de la energía mítica: cambios de paradigma en el mito, 2. La iconografía de la libido freudiana: el imaginario edípico, 3. El imaginario edípico se urbaniza: la puesta en escena del rito de la castración, 4 . El triunfo de la fantasía freudiana: la retórica libidinal del objeto de consumo, 5. La desedipización del inconsciente: el cuerpo sin órganos, 6. La libido internauta: La codificación y descodificación del flujo de información, 7. El rito bajo el Complejo de Electra: la antropología de los programas perversos. Referencias.
\end{abstract}




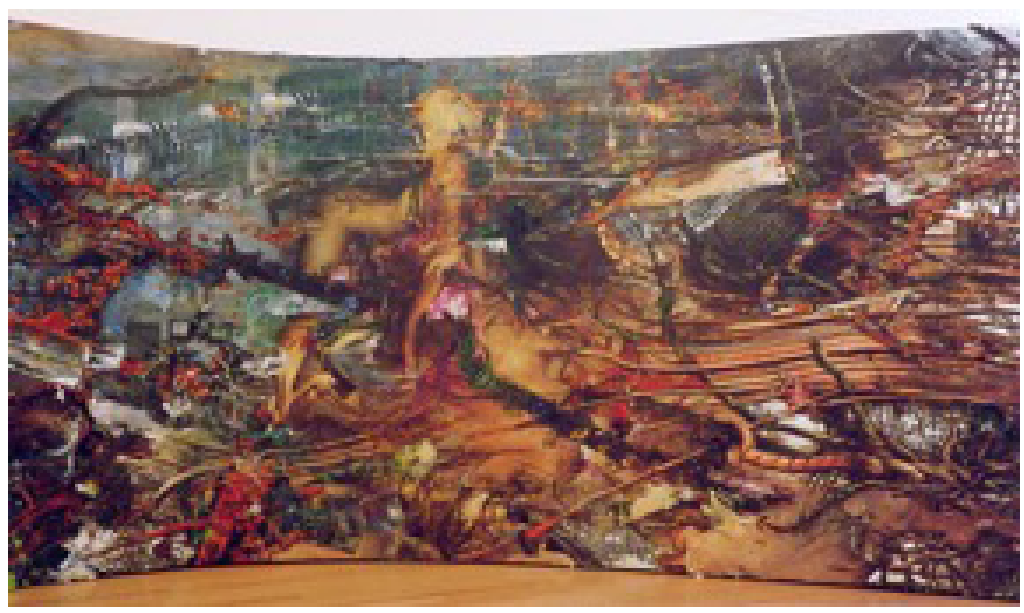

Figura 1. Fabian Marcaccio: Energía-líbido-información. 2004. (Procedente de www.paintantscorporation.com).

\section{La transformación de la energía mítica: cambios de paradigma en el mito}

El mito, como la energía, no se crea ni se destruye, sólo se transforma. Si la mitología asume esta ley fundamental de la energía, entonces la crónica del mito será también el relato de sus distintas fuentes materiales. Según esta energética mitológica los mitos cambian de forma en el tiempo porque cambian de yacimientos materiales: un mito puede brotar de los elementos naturales, hacer hablar a la fauna salvaje, nutrir la tradición oral o la visión artística, fundamentar religiones o avances técnicos, pero su naturaleza esencialmente anacrónica muta con cada reencarnación material. En consecuencia, esta transubstanciación del mito responde a los mismos cambios de paradigma que el analista de la ciencia Thomas S. Kuhn descubrió en las sucesivas revoluciones científicas (Kuhn, 1975, 13) una estructura de concepciones diferentes del mundo que modifican la ideas de materia y energía a lo largo de la historia.

El manantial energético de la mitología griega, según esta historia paradigmática, sería el cosmos presocrático, donde el elemento agua descrito por Tales de Mileto tendría una afinidad epistemológica con el Océano de Homero (Alemany y Repollés, 2013, 35-44). Los mitos arcaicos griegos emanaron del manantial natural gracias al imaginario hídrico de los aedos y, como ríos que bebían de distintos afluentes, crecieron con las aportaciones helenísticas, renacentistas, isabelinas o románticas y sus respectivos paradigmas hasta desembocar en el océano de la modernidad. Actualmente, la cibernética aporta su imaginario electrónico a esta larga travesía del mito griego (Alemany, Perandones y Repollés, 2014) gracias a Sigmund Freud, quien a finales del siglo XIX logró desmaterializar los manantiales de energía mítica entendiendo este caudal mitológico como una fuerza psíquica intangible a la que denominó energía libidinal.

En efecto, gracias al padre del psicoanálisis la mitocrítica puede estudiar las diversas sustancias sagradas de los mitógrafos clásicos como una única fuerza psíquica, fundamento antropológico del imaginario mitológico entendido desde el 
prisma del deseo. El maestro vienés advirtió que el mito, el arte y la religión de la antigüedad procedían del mismo manantial energético que descubrió en sus estudios clínicos gracias al paradigma de la metapsicología, teoría que pasó a ser la explicación hegemónica de la física y la dinámica del inconsciente durante el siglo XX.

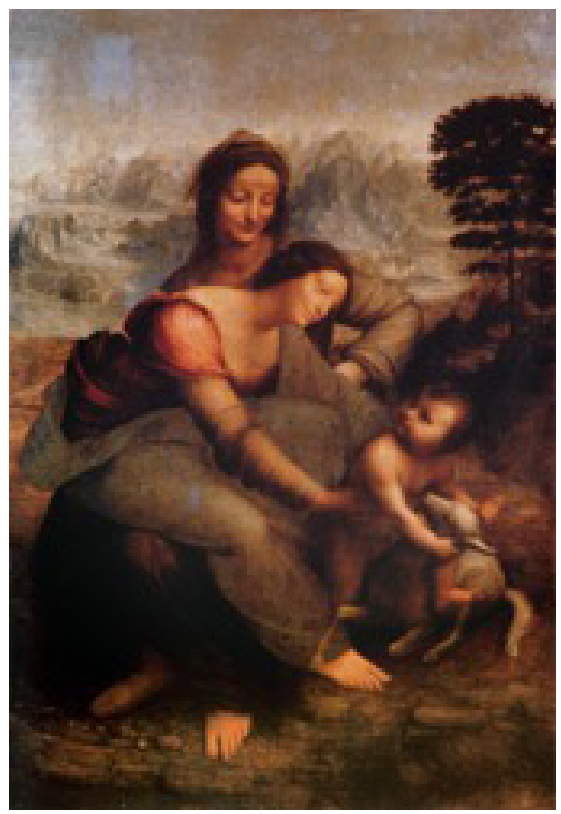

Figura 2. Leonardo da Vinci: Santa Ana, la Virgen y el niño, 1510. Musée du Louvre.

(Disponible: www.louvre.fr/en/expositions/saint-anne-leonardo-da-vinci).

Hoy en día, cuando los físicos teóricos conjeturan sobre realidades cósmicas tales como la materia oscura y la energía oscura (Ostriken y Mitton, 2014) muy superiores en proporción a la materia común del universo, la comunidad científica no se hubiera escandalizado tanto como en 1895 a la hora de admitir la existencia de una fuerza psíquica capaz de ejercer una influencia tan poderosa sobre los cuerpos como la gravedad.

La demostración de la libido freudiana necesitó del imaginario artístico, que Freud relacionó con la lógica de la formación de los sueños, vinculando los enigmas existenciales de los artistas con la hermenéutica de las obras de arte. La interpretación de Santa Ana, la Virgen y el Niño a partir de un recuerdo infantil de Leonardo da Vinci (Freud, 1996-B, 1593) fue un estudio pionero en el enfoque libidinal de la creación artística y un hito en la teoría del arte moderno, que desde entonces aportó el carburante de la libido como principal combustible artístico que las vanguardias históricas explotaron del mismo modo que la industria del motor hizo con el petróleo.

A pesar de esta supremacía energética del inconsciente freudiano en las ciencias del hombre y las vanguardias, el advenimiento de la neurociencia (Damasio, 2010) ha supuesto una crisis del paradigma psicoanalítico y está cuestionando seriamente el determinismo freudiano y sus interpretaciones en exceso sexuales. Recientemente, 
el estudio neurológico del deseo está desplazando la topología de la libido desde los órganos genitales a las áreas cerebrales, desde una concepción tecnológica que se circunscribe a los procesos cognitivos y se aleja cada vez más de la consideración freudiana del deseo.

A pesar de este cambio de paradigma, no es posible comprender la extraña mutación del imaginario freudiano en digital sin asumir su refinamiento previo en el ámbito de la creación artística y en los objetos de consumo del siglo XX, un desplazamiento de la energía libidinal desde la neurosis a la neurociencia que ha propiciado la ulterior transformación del deseo en pulsión digital. Con esta mutación, el estudio de la iconografía mitológica se enfrenta a importantes cambios (en la diacronía) del imaginario edípico instaurado por Freud y el surrealismo (en la sincronía) de los rituales electrónicos establecidos por los nuevos nativos digitales y los dispositivos electrónicos de Internet.

\section{La iconografía de la libido freudiana: el imaginario edípico}

La concepción freudiana del inconsciente supuso una verdadera revolución en el ámbito de las ciencias médicas y del hombre (Fougeyrollas, 1971). Freud pretendía dar nombre e imagen a regiones de la mente que hasta entonces solo habían sido descritas introspectivamente por la filosofía o reducidas a biología por la psicología. Freud presenta la libido como una inercia vital cuya energía anima al hombre, aquejado por tensiones ocultas que superan con creces la dimensión consciente. A partir de sus estudios sobre la histeria, la gramática de la expresión libidinal del neurótico le llevará al estudio de las obras de arte, que interpretará mediante el simbolismo de los sueños entendidos como realizaciones oníricas de deseos inhibidos.

Esta necesidad de realización onírica del deseo es precisamente la que impulsa a los hombres a actuar conforme a presiones inconscientes y se percibe gracias a la tensión bipolar que experimentan los cuerpos cuando están aquejados por síntomas neuróticos. Para acotar el alcance de la energía libidinal Freud dispuso entonces de los polos mitológicos del Eros y del Thanatos (Freud, 1996-C, 2674-2676) entre los cuales oscilaría esta insólita fuerza psíquica que dividía al sujeto entre el principio del placer (el inconsciente) y el principio de realidad (la moral).

Tanto los mitos griegos como el psicoanálisis freudiano coinciden en alegorizar las pasiones del hombre proyectándolas en un universo onírico. Los griegos dieron una explicación sexual a las relaciones astrológicas entre los planetas como cópulas entre dioses antropomórficos, del mismo modo que el psicoanálisis describe las pasiones humanas a partir de las fuerzas motrices del universo. Esta es la razón por la que Peter Gay expone en su biografía sobre Freud que el psicoanálisis es un método newtoniano al subordinar las leyes de la mente a las del movimiento (Gay, 2010, 107). Y este carácter psicofísico de la libido freudiana fue la excusa perfecta para que sus detractores recurrieran a la vieja disputa entre mecanicistas y vitalistas con el fin de desacreditar el polémico método.

Con el paso del tiempo han podido esclarecerse las aportaciones freudianas de sus excesos positivistas o pansexualistas, pero es un hecho incuestionable que Freud descubre el inconsciente y su implacable mecánica, decodificada a partir de toda una teoría de la represión (Verdrängung). Fue precisamente para comprender las 
causas de la represión de la libido, inequívocamente ligada a las imposiciones de la moral burguesa de la época, que el neurólogo se hizo mitólogo y formuló el complejo de Edipo en 1923 arrebatando a Sófocles la exclusiva del héroe trágico. El destino de Edipo Rey, sus avatares designados por los oráculos, sus relaciones familiares incestuosas y patricidas, fueron rescatados por Freud como arquetipo del neurótico marcado por las leyes inescrutables del inconsciente. Edipo es el icono freudiano de la represión pues, no en vano, su drama termina con el estigma de la castración simbólica, un fenómeno universal que da acceso al orden simbólico (Freud, 1996-A, 2700-2728).

El mito edípico también es la clave del correspondiente rito de castración que garantiza al neurótico, al niño o al salvaje, el acceso a la cultura, es decir, al malestar de la cultura, como parte de la represión inherente a la civilización. Por ello, a medida que el psicoanálisis se especializa, la teoría del Edipo encontrará numerosas aplicaciones en los textos freudianos y, sobre todo, el icono del héroe tullido reaparecerá como la muletilla recurrente para explicar la mecánica reprimida de la libido en el imaginario. Edipo no sólo dará un arquetipo a la metapsicología sino a buena parte de la iconografía artística del siglo XX. Y el propio Freud no hará más que ampliar el imaginario edípico relacionándolo con iconologías afines, tales como la cabeza de Medusa, el buitre de Leonardo, el pie de Gradiva, etc., que en aquellos años irán conformando un verdadero catálogo de fantasmagorías de la castración.

Como trofeos de caza decapitados, estos fetiches de la hermenéutica psicoanalítica adornaron el gabinete de Freud y después se hicieron comunes en los despachos de los terapeutas en forma de máscaras africanas, figuras votivas, metopas clásicas o ídolos antropomórficos que recordaban a los pacientes sus traumas originarios, es decir, la genealogía fantástica de su malestar: que a menudo se remontaba a alguna escena de castración.

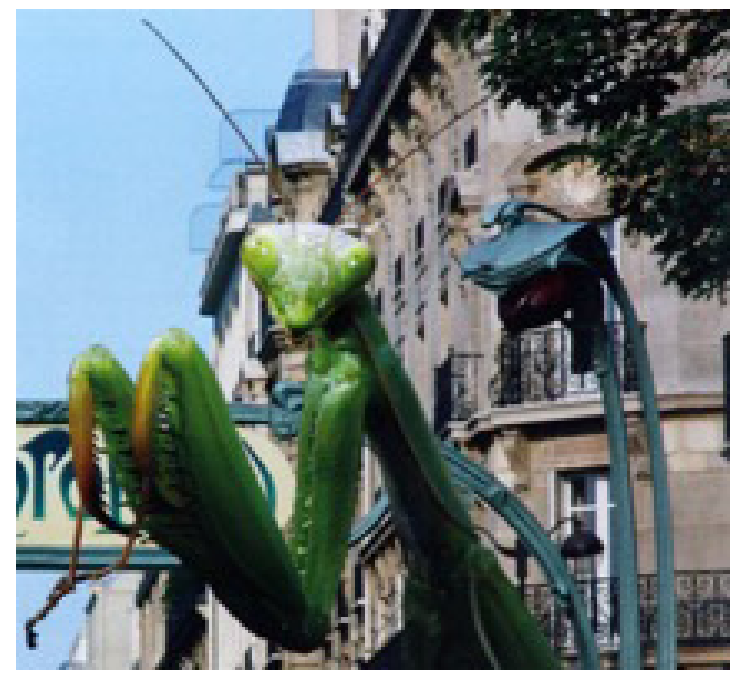

Figura 3. Frédéric Descouturelle, André Mignard y Michel Rodríguez:

Comparación de las farolas de acceso al metro de París con una mantis religiosa. 2012 (Disponible en: Descouturelle, F. et alt. [2012]). 


\section{El imaginario edípico se urbaniza: la puesta en escena del rito de la castración}

Más allá de la catarsis propia de la terapia psicoanalítica, basada en el potencial psíquico de la palabra, la finalidad terapéutica de las sesiones consistía en liberar al neurótico del bloqueo subyacente a su represión mediante descarga (o catarsis) de las fuerzas psíquicas largo tiempo reprimidas en el subconsciente. El uso terapéutico de estos fetiches de la castración a menudo no pasaba de su adoración idolátrica cuando, más bien al contrario, el neurótico debería acceder a su trasgresión ritual. En efecto, como la esfinge de Edipo, estos fetiches de gabinete albergaban el secreto de la represión neurótica, y fueron empleados con este fin por algunas vanguardias históricas al dictado de la liturgia freudiana.

No hubo que esperar muchos años para que la iconografía freudiana se transcribiera a la gramática surrealista a partir de fórmulas extendidas a otras figuras de la tradición, como es el caso de Cristo castigado por María (Max Ernst) o la amenaza de castración de Guillermo Tell (Salvador Dalí). Buena parte de la genealogía del imaginario libidinal en el arte moderno y contemporáneo invoca estos fantasmas neuróticos que retornan del pasado reprimido para mantener al hombre atenazado con toda suerte de espectros hamletianos (Repollés, 2011).

En este sentido, existe en la ciudad de París toda una tradición de circuitos urbanos surrealistas que comienza con el flâneur de Baudelaire, se consolida en las anamnesis de los Pasajes de Benjamin y culmina mucho después con las situaciones de Guy Debord (Debord, 1997), convirtiendo la capital francesa en un verdadero yacimiento arqueológico del retorno de lo reprimido. Los surrealistas, como colectivo neurótico especialmente libidinoso, propiciaron diferentes acciones urbanas que convocaran a estos fantasmas del pasado entre los que destaca la inquietante epifanía de la mantis religiosa en el suburbano diseñado por Hector Guimard en 1900. Es conocida la belleza convulsa de las elegantes entradas del metro parisino diseñadas por el maestro modernista, que aún pueden verse en algunas estaciones art noveau. Según la fantasía de los surrealistas, estas sugestivas bocas de metro se transfiguraban en mantis religiosas, sin duda por asociación de las farolas del suburbano con el temible insecto verde de enormes ojos alienígenas (Descouturelle, 2012, 196-213).

El insecto mantodeo, que por su etimología denota una sección interior (insecto) se acompaña de una entomología legendaria por el mito de la decapitación del macho tras la cópula, un verdadero filón de la fantasía de castración. La religiosa de Guimard fue establecida, por tanto, como un tótem de la castración simbólica justamente cuando el ciudadano neurótico conjuraba su miedo ancestral a penetrar el inframundo.

Los surrealistas fantasearon con el insecto de turbadora vida sexual a partir de los textos de Roger Caillois (Caillois, 1998, 39-93) y Dalí (Dalí, 2002) que lo elevaron a tótem entomológico y vegetal. Quizá por las florituras ornamentales del metro de Guimard, con evidentes alusiones a la anatomía sexual, el implacable acto sexual de la mantis encajó bien en el ornamento del suburbano. No hay que olvidar que, según la analogía freudiana, existe una equivalencia estructural entre decapitar y castrar (Freud, 1996-A, 2697) motivo por el cual la fantasía de la mantis era también un fantasma ya durante la Revolución Francesa, cuando la decapitación formó parte 
de la mecánica de la emancipación civil y se instaló un imaginario de la guillotina (Arrase, 1987).

El movimiento simbolista mantuvo esta fantasmagoría de cabezas decapitadas en las pinturas de Odilon Redon y Gustave Moreau, y la psicosis colectiva generó su recurrencia simbólica desde la cabeza de Medusa sostenida por Perseo a las sucesivas decapitaciones rituales revolucionarias, surrealistas y fascistas (Kristeva, 1998); fenómenos y periodos donde se expresó más que nunca el temor arcaico a la pérdida de la razón ante la llegada de un nuevo orden simbólico y que en Estados Unidos propiciaría igualmente la figura del jinete sin cabeza de Washington Irving.

Esta iconología moderna de la castración/decapitación tuvo un momento de autoconciencia sublime de la mano del sociólogo francés Georges Bataille, quien elevó el icono del Acéfalo, un ser liberado de la moral y, por tanto, de la cabeza (Bataille, 2005) sumándose a toda una genealogía de la castración/decapitación en las figuras bíblicas de Salomé con la cabeza de Juan el Bautista o Judit con la cabeza de Holofernes (Bataille, 1997) que comparten con la Gorgona Medusa y la mantis religiosa, también llamada Santa Teresa, la secuencia ritual de la cópula y la castración/decapitación.

Como recuerda Jean Clair, esta amenaza de castración sería completamente inofensiva sin la correspondiente visión neurótica de la mujer asegurada por el estigma de los genitales femeninos como fuentes de impurezas (Clair, 1998). Freud además de achacar estas cuestiones a la carencia de pene (pennisneid) consideró al sexo femenino de manera ambivalente como castrado y castrador. En resumen, este tipo de temores y supersticiones primitivas ante la visión del origen del mundo serían catalizadores de la libido simulandi del imaginario mítico edípico y su ritual de castración, descrita por Freud precisamente como la consecuencia trágica de la represión necesaria para que el subconsciente quede en el sótano de la vida consciente de la cultura.

\section{El triunfo de la fantasía freudiana: la retórica libidinal del objeto de consumo}

Según la termodinámica, la existencia del vacío es necesaria para que pueda circular la energía. Igualmente, Freud aseguró que la mecánica del deseo procede de una carencia originaria, de un vacío. La clínica de esta falta en el deseo fue descrita por el revisor del legado freudiano, Jacques Lacan, como la angustiosa ausencia/ aparición de alguna fantasía libidinal: ya sea el falo imaginario (del padre) o el pecho alucinado (de la madre). Esta relación con el objeto de deseo perdido y anhelado hasta la alucinación es la que mueve al sujeto hacia el deseo del Otro y, en todo caso, genera toda suerte de fetiches sexuales (Lacan, 2004).

Como es sabido, Freud fue pionero proyectando falos imaginarios sobre obras de arte del pasado, como es el caso del buitre materno sobre el drapeado pintado por Leonardo (figura 2). Ni siquiera Cristo crucificado escapa a esta falofanía, como bien ha demostrado el estudioso Alexandre Leupin al descubrir asombrosos falos fantasmagóricos inscritos en el icono por excelencia de la cristiandad (Leupin, 2000). Este delirio edípico se ha generalizado en el mundo del arte con la visión de pechos, vaginas y falos subliminales por doquier, aunque la disciplina libidinal más explícita 
ha sido la escultura, con el levantamiento de tótems fálicos por parte de Brancusi, Henry Moore, Louise Bourgeois o Anish Kapoor (Alemany y Repollés, 2011, 8-15).

La segunda posguerra dará lugar a un esplendor del imaginario fálico cuando Edipo abandone los restringidos foros de la terapia psicoanalítica y de las vanguardias, banalizado por la cultura pop y el triunfo de la sexualidad en la publicidad y el cine. El imaginario de la sociedad de consumo sufrirá una implantación masiva de fetiches eróticos en los spots televisivos, que explotarán demasiado a menudo la grosera fantasía de las carencias del ama de casa obteniendo su bienestar a partir de algún instrumento de limpieza. El deseo y su carencia es el centro de toda la retórica del objeto de consumo, invariablemente destinado a satisfacer las falsas necesidades de la economía capitalista. Una energética del consumismo que ya fue explicada por Karl Marx como fetichismo de la mercancía: ensoñación relacionada con la plusvalía del objeto que explica el excedente erótico o sex-appeal de todo producto y su poder de atracción sobre las masas (Marx, 1984).

El imaginario edípico afectó a la noción marxista de mercancía, cumpliendo el viejo sueño de André Breton de conciliar el movimiento surrealista con el comunista en el año 1925. Al fin y al cabo, el surrealismo, a través de Benjamin, está en la génesis de la Escuela de Francfort, el estructuralismo cultural y la crítica posmoderna, y de autores tan distintos como Herbert Marcuse, Jean Baudrillard o Slavoj Zizek. Marxismo y freudismo se aúnan para analizar la cultura de masas según la dialéctica del Eros y el Thanatos (Marcuse, 1963). De hecho, en los últimos años ha surgido toda una antropología dialéctica de la obtención y la pérdida de la libido transferida al objeto de consumo, inaugurada también por Freud con su reflexión sobre el niño que juega lanzando lejos de sí un carrete de hilo para luego recogerlo: oscilación bipolar entre el alejamiento y la cercanía del objeto (fort-da) según el principio del placer. En este bucle infinito de obtención y pérdida del objeto se hubiera enrocado la historia de la libido si no fuera por la llegada del paradigma de Mayo del 68, la hiperrealización del deseo promulgada al grito de jla imaginación al poder!

\section{La desedipización del inconsciente: el cuerpo sin órganos}

En efecto, se debe a los pensadores franceses posmodernos la crítica de la mecánica freudiana mediante la cual el capitalismo avanzado genera necesidades y carencias asociadas a una libido adherida a los objetos de consumo (Baudrillard, 2007). Pero los autores post-marxistas y post-freudianos quisieron escapar de esta concepción restrictiva de la economía libidinal -que explica toda oferta como la satisfacción de una demanda y toda demanda como el deseo de satisfacción (imposible) de tal carencia- explorando los dispositivos pulsionales (Lyotard, 1984) que transforman la plusvalía de código en plusvalía de flujo, es decir, el deseo en realidad.

Gilles Deleuze y Félix Guattari emprenderán la subversión del pesimismo moral freudiano y su consecuente producción de libido reprimida y neurotizada con el firme cuestionamiento de que el deseo proceda de una falta o una carencia. Tal es la premisa de El Anti-Edipo de 1968, un manifiesto contra la falta en el deseo freudiano y contra toda representación del inconsciente mediante fantasías edípicas (Deleuze, 1998). El pensador francés acusa al psicoanálisis de cómplice del Capital por describir un 
inconsciente castrado y represor proponiendo la desedipización de la libido, es decir, la abstracción del deseo de todo sentimiento de culpa, al que está vinculada dicha carencia y, en última instancia, toda representación freudiana del deseo como trauma familiar.

Deleuze muestra el imaginario freudiano como un teatrillo familiar donde el neurótico identifica las fantasías con las distintas figuras totémicas relacionadas con sus traumas infantiles. Según el pensador francés el inconsciente quedaría liberado de sus moldes freudianos, de su fantasmagoría edípica y podría explorar la capacidad energética de la libido para producir realidad. Para Deleuze el Ello no representa nada, no significa nada, no se puede interpretar ni moralizar, no genera culpa ni carestía porque es inagotable, como las fuentes míticas, es una máquina de producción deseante (Deleuze, 2005).

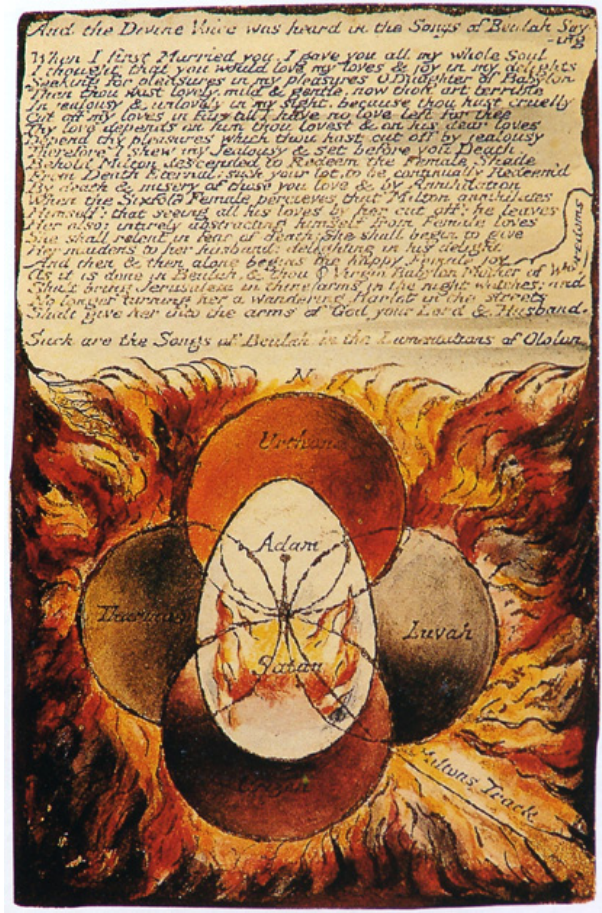

Figura 4. William Blake: El huevo cósmico. 1808. Ilustración de Milton. The William Blake Trust. (Disponible en: www.blakearchive.org/cosmic-egg).

Según el Anti-Edipo la libido no produce deseos reprimidos ni fantasías neuróticas de sujetos atemorizados por la culpa y la amenaza de castración, produce potencia esquizofrénica de realidad. De este modo, la libido deleuziana está vinculada a las vanguardias abstractas -así como a las representaciones no-figurativas- tal y como la freudiana estaba ligada a las atormentadas expresiones surrealistas. Deleuze se suma de este modo a la estética contemporánea francesa, que entonces progresaba del surrealismo al nuevo realismo, pues la superación del psicoanálisis pasa por la 
abstracción de la realidad de toda representación. Como desarrollará José Luis Pardo, un espacio radicalmente exterior al lógos supone una teología perversa en la cual "el fantasma no designa una ilusión, sino justamente la verdad de la producción de lo real" (Pardo, 2011), lo que supone la producción de realidad como simulacro.

En relación a esta utopía de una realidad libidinal, consumada ahora gracias a la realidad virtual de Internet, Marx había mostrado al capitalismo como una gran máquina que convertía el trabajo, es decir, la fuerza de trabajo, en una especie de masa de energía amorfa y descualificada que no podía ser encarnada por ningún obrero o gremio especializado. Esta primera abstracción del trabajo artesano en pura descarga de energía cuantificable permitiría la conversión de la realidad en producción de flujo económico conllevando la transfiguración alquímica de la fuerza de trabajo en flujo de capital.

Pero la imagen de esta máquina automática que ha sustituido a la realidad como un simulacro de producción de deseo que nunca paraliza ni reprime su flujo y reflujo obligó a Deleuze a dar con una figura mito-lógica: el huevo cosmogónico de los relatos paganos al que denominará el cuerpo sin órganos una reminiscencia del huevo Dogón africano y del huevo caótico de Ovidio: Todo viene del huevo, ex ovo omnia (Deleuze, 1997, 155-171).

Naturalmente, la imagen del huevo estaba muy presente en la propia tradición libidinal del surrealismo y del simbolismo, pues William Blake escogió el huevo cósmico de la alquimia (figura 4) como el receptáculo de la intersección de las cuatro fuerzas primarias del universo descritas en su esquema místico del ser humano (Roob, 2001, 119). Así como Freud acudió al mito de Edipo para dar una imagen del neurótico reprimido y Blake sitúa las fuerzas del huevo entre los polos míticos de Adán y Satán, principio y fin, muy similares a los polos del Eros y el Thanatos, Deleuze acudió al modelo ovoide del cuerpo sin órganos para desplegar la máquina abstracta de inmanencia donde se realiza la producción deseante de realidad. Este modelo supondría la convergencia de mitología y embriología, sería por tanto un huevo libidinal capaz de producir realidad sin intrusión alguna de la conciencia, un medio de intensidad pura, el spatium, la intensidad absoluta como principio de producción de una realidad más allá de la metapsicología.

\section{La libido internauta: la codificación y descodificación del flujo de información}

A pesar de que Internet no existía cuando Deleuze ideó su cuerpo sin órganos, no deja de ser paradójico que la implantación de la sociedad-red sea producto de este flujo y reflujo permanente del deseo en un medio electrónico intensivo, codificado y descodificado por los sistemas de información. El usuario es arrastrado sin posibilidad de detenerse en una significación, en un relato o ni siquiera en una representación. Internet no es una pantalla donde proyectar fantasmas del principio del placer sino una fantasmagoría convertida en principio de realidad; porque su flujo imaginario nunca se detiene en un icono, un discurso o un objeto, es la imagen prístina del caos originario y prehistórico de los relatos míticos. En efecto, la red provee al nuevo nativo digital de suficientes dispositivos como para celebrar catarsis diarias, perder su identidad en el grupo, zambullirse en la red, como antaño el salvaje se confundía con 
la naturaleza, y satisfacer lo que no puede denominarse sino como linkbido.

Una nutrida selección de contenidos digitales permitiría al nativo pasar de una sensación a otra sin mediación ninguna del logos y sin detener jamás su producción deseante de realidad a no ser por la última crisis de energía. Porque la historia del sistema capitalista es la historia de sus crisis energéticas y en 2008, junto con la crisis financiera internacional el filósofo coreano Byung-Chul Han ha diagnosticado una crisis del Eros (Han, 2014). Para Han la extenuación del deseo en la llamada sociedad del cansancio está produciendo una cultura digital melancólica, escasa de libido, y un mundo narcisista en el que ya no cabe el deseo del otro. Sucede como si el usuario de la red, atrapado en el bucle ovoide del cuerpo sin órganos, cargase y descargase su deseo sin asomo de alteridad. Pero la energética mitológica debe evitar recaer en el esquematismo moral de Han, quien repite el error de Freud a la hora de analizar la carencia del sujeto fetal y narcisista que se incuba en este bucle electrónico. La interpretación melancólica de la pérdida del Otro es contraria al espíritu de Internet, basado en la interactividad, que ya no reproduce imágenes fetiches (postales, revistas, fotogramas) sino links, conexiones o relaciones entre múltiples acciones. Internet está produciendo rituales comunitarios inauditos para el estudioso occidental.

La libido digital está operando, mejor que ningún otro dispositivo surrealista, lo que Lyotard llamó "la presencia del no-lenguaje en el lenguaje" (Lyotard, 2014) la programación del deseo como realidad. Ya el psicoanálisis adulto de Lacan había formulado que el deseo freudiano, a través de la filosofía del lenguaje, pasaría a ser un significante en la economía del deseo, según la fórmula de un sujeto abierto al deseo del otro, a la demanda de deseo en el otro (Lacan, 2006, 830-833). Por esta razón, el advenimiento de la cultura electrónica fue saludado con entusiasmo por parte de los ideólogos de la comunicación de los años 70 . Un verdadero renacimiento del pensamiento salvaje advenido con la lectura integrada de los mitos populares, el cómic, la televisión, la radio y el cine. La utopía posmoderna del progreso tecnológico favorecería de este modo a la sensibilización del viejo Occidente hacia el pensamiento primitivo y oriental. Marshall Mc Luhan fue el gurú de esta utopía que anunciaba la llegada de la aldea global donde el hombre civilizado explotaría nuevamente el hemisferio derecho del cerebro, avasallado por la rígida alfabetización secuencial y lineal del hemisferio izquierdo, reprimido por el logos desde la invención de la imprenta (McLuhan y Powers, 2011). La era electrónica suponía el triunfo del lógos, como entorno programado por el deseo, a la vez que su aniquilación como espacio virtual y mítico.

El posterior advenimiento de la cultura digital fue anunciado con mayor optimismo aún como el retorno del alfabeto fonético, la oralidad, el espacio táctil, acústico, simultáneo y multi-sensorial garantizado por los dispositivos electrónicos en aras de una concepción holística, comunitaria, emocional y musical de la cultura que acogería las sensaciones echadas en falta por el imaginario hardware del hombre decimonónico. La industria de la imagen, vinculada a las pantallas de cine, la televisión y las revistas, se renovó en Internet, cuando la búsqueda de placer narcisista de los nuevos nativos digitales erradicó la cultura del libro y del formato plano en beneficio de la interacción social. En palabras de Michel Serres "las nuevas tecnologías obligan a salir del formato espacial implicado por el libro y por la página" (Serres, 2014, 
50). Las implicaciones de esta sustitución de la cultura del libro y del imaginario literario sobre la conciencia del nativo digital aún son impredecibles, pero lo que es seguro es que el imaginario sexual freudiano se transformó en digital precisamente por la realización del deseo en el elemento electrónico mediante la implementación de insólitos programas perversos como los que Deleuze definió precisamente para construirse un CsO: ni un cuerpo ni una imagen, un conjunto de prácticas.

Internet es anti-edípico por naturaleza. El internauta es incapaz de otorgar un discurso al flujo de imágenes, una genealogía totémica a sus fantasías, incluso una legislación a los acontecimientos que suceden en la red. Pero esta imposibilidad de otorgar un orden, un sentido, una ley, en definitiva un logos al flujo digital del ciberespacio, genera un espacio ritual ideal para los programas perversos. Internet es la plataforma del cuerpo sin órganos donde el nativo digital se propone hacer un plan de producción de realidad, basado en el ocultamiento de su identidad, la búsqueda de contactos sexuales, la celebración de happenings colectivos y demás prácticas establecidas por las redes sociales con más o menos conexión con las prácticas artísticas del net-art (Martín Prada, 2012).

Al fin y al cabo, los mitos siempre han sido manifestaciones rituales colectivas, inconscientes y performativas, puramente interactivas. Los rituales electrónicos que desarrollan los adolescentes en comunidades on-line a través de máscaras virtuales, están planteando una situación antropológica propicia para el trabajo de campo sobre el rito digital y su imaginario electrónico. La revolución freudiana, que comenzó ayudándose de la electro-estimulación y la hipnosis para extraer de los cuerpos histéricos verdaderos discursos -sensibles a través del lapsus, los actos fallidos, los síntomas o los ataques histéricos- está en el origen de la libido digital, que opera codificando y descodificando los cuerpos de los usuarios en energía electrónica y digital, eyaculada y emasculada cual energía de una batería.

Quizá el artista que mejor ha puesto en esta codificación/descodificación permanente del flujo de información digital en cuerpos libidinales es el pintor argentino Fabian Marcaccio, en cuyos soportes pictóricos ondulados no cesan de tejerse y destejerse las imágenes mediáticas como flujos de información que a su vez se transforman en carnosas masas de cuerpos, conceptos e ideologías libidinales (Marcaccio, 2014, 62-63). Marcaccio teje sus pinturas de este modo, como se teje la libido en el sistema-red, a partir de cuerpos significantes de un alto contenido erótico o tanático que son adheridos en una estructura-red como materia electrónica y libidinal. 


\section{El rito bajo el Complejo de Electra: la antropología de los programas perversos}

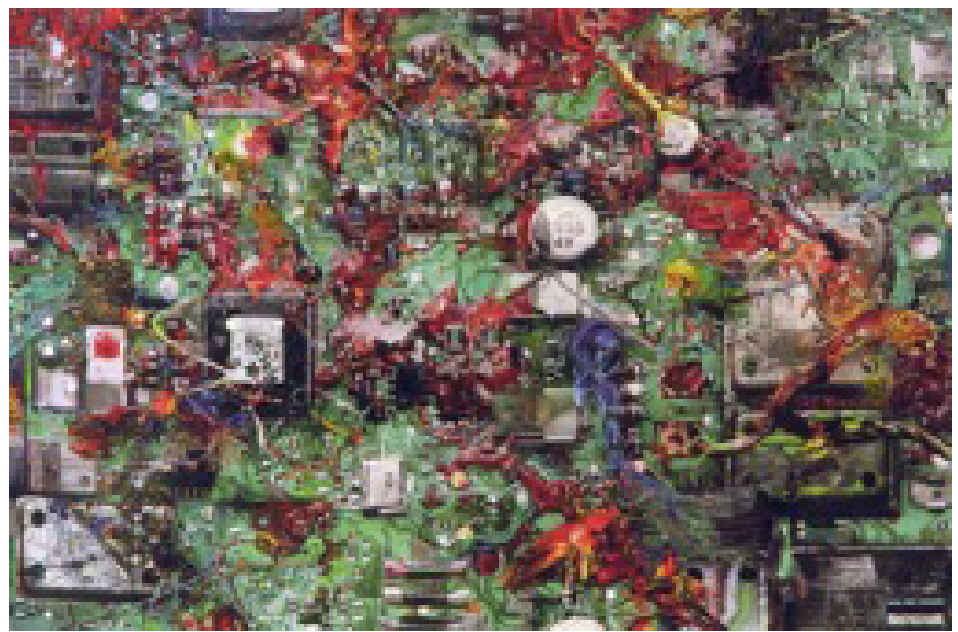

Figura 5. Fabián Marcaccio: Re-bocetando la democracia. 2004.

(Disponible en: www.paintantscorporation.com).

La mitocrítica se enfrenta a un escenario de interpretación de los ritos en el que debe hacer abstracción del lenguaje, y de la propia cultura del libro, para estudiar los acontecimientos digitales, que no suceden ya en tribus remotas sino en Internet, cada vez que un adolescente accede a un ritual de carga y descarga de la autarquía de la libido mediante un programa perverso destinado a su satisfacción electrónica. La libido digital puede ser tan binaria como la tensión freudiana entre Eros y Thanatos pero está articulada con un bucle narcisista que comienza con la carestía de objeto (freudiana) y se pliega con la falta en el sujeto (lacaniana) como una cinta de Moebius iterativa entre dos polos electrónicos. Por tanto, la libido digital y el imaginario perverso de Internet completan el largo proceso histórico que comenzó en el siglo XIX cuando el obrero cargó su fuerza de trabajo sobre la máquina capitalista para ser descargada en forma de libido electrónica por parte del usuario del sistema-red. El Narciso digital se descarga su propio flujo libidinal a través de un dispositivo: mecánica onanista, que los surrealistas anticiparon con las máquinas solteras de Duchamp y, en todo caso con los polos neuróticos estudiados por Freud.

Pero ¿qué es lo que renueva el incesante acceso de los nativos digitales a Internet en busca de nuevas descargas? Si Deleuze encontró en el cuerpo sin órganos el mito del ciclo autónomo del deseo sin mediación de la conciencia ¿qué mito opera la energética del deseo en ese bucle? Zizek ha interpretado el catalizador del deseo precisamente como ese bucle, a través del petit objet a minúscula, un constructo teórico lacaniano que describe el permanente rodeo del deseo respecto de su objeto (Zizek, 2006). La historia del imaginario libidinal tiende a este bucle energético. Después de que Edipo se arrancara los ojos para no ver cumplido su destino, parece que el cuerpo sin órganos de Deleuze, o el petit objet a de Lacan, se hubieran alojado de nuevo en la cuenca ocular. Ya sea una imagen centrípeta del huevo como superficie 
intensiva de circulación de la libido, o una imagen centrífuga de los límites del circuito del deseo, estas teorías posmodernas coinciden en la circunscripción de la libido en torno a un vacío. Este vacío electrónico puede ser visto como contenido (Edipo) o un continente (Electra).

La dualidad Edipo-Electra ha supuesto un aluvión de interpretaciones feministas y anti-freudianas del complejo de Edipo a partir del mito de la hija de Agamenón y Clitemnestra, nacida del huevo de Leda junto su hermana Helena y sus hermanos Cástor y Pólux. El amor al padre y el odio a la madre fueron denominados por Freud como un complejo de Edipo femenino pero gracias a Jung desde 1912 se conocen como complejo de Electra (Jung, 2000), inaugurando una interpretación del mito, más allá de la envidia del pene, según el paradigma posmoderno. Electra o Laódice puede ser la contrafigura del Edipo, el Anti-Edipo cibernauta que acude a la red a satisfacer sus fantasías mediante lo figural digital siguiendo un rastro de huellas virtuales, de sexualidad intensiva y deslocalizada, de desplazamientos de identidad y alteraciones complejas del espacio-tiempo. Porque Electra no se arranca los ojos como el voyeur edípico, sino que ofrece su cuerpo a la producción deseante, idealmente tejida por Aracne, otra hermosa fábula sobre la decapitación/castración femenina para el sistema-red.

Electra puede ser el icono del imaginario libidinal cuando fluye por el interior de la matriz, allí donde no existe la culpa prometeica derivada del robo de las descargas de Zeus, ni su amenaza de castración. La sexualidad de Electra ya no es edípica, no se localiza en fetiches fálicos de consumo, pues, en los términos de Freud, el cursor no tiene envidia del pene. Puede que el Complejo de Edipo y su imaginario haya mutado en el Complejo de Electra, o puede que ambos sean el derecho y el revés del mismo complejo energético, generador de un nuevo imaginario que está por descubrir en los rituales electrónicos del nativo digital.

\section{Referencias}

Alemany, V. y Repollés, J. (2013). "La substancia del mito: una recuperación del valor mitológico de las substancias elementales en la creación plástica contemporánea." En Mito e interdisciplinaridad: Los mitos antiguos, medievales y modernos en la literatura y las artes contemporáneas, editado por José Manuel Losada y Antonella Lipscomb. Bari: Kleos. 35-44.

Alemany, V., Perandones, E y Repollés, J. (2014). "La ondina digital: Apariciones

posmodernas de la ninfa acuática en el imaginario del algoritmo digital" En ArDIn, Arte, Diseño e Ingeniería, Volumen 0, Revista digital adscrita a la Universidad Politécnica de Madrid.

Alemany, V. y Repollés, J. (2011). "Represión y sublimación: sexualidad explícita e implícita en las representaciones de Cristo" En Sexo Implícito/Explícito, editado por la Facultad de Bellas Artes. Madrid: BBAA. 8-15.

Arasse, D. (1987). La guillotine et l'imaginaire de la Terreur. París: Flammarion. Bachelard, G. (1994). El agua y los sueños. Madrid: FCE.

Bataille, G. (2005). Acéphale. Buenos Aires: Caja Negra. 
Bataille, G. (1997). Las lágrimas de Eros. Barcelona: Tusquets.

Baudrillard, J. (2007). La sociedad de consumo. Madrid: Siglo XXI.

Caillois, R. (1998). El mito y el hombre. México: FCE.

Clair, J. (1989). Méduse. París: 1989.

Dalí, S. (2002). El mito trágico del Ángelus de Millet. Barcelona. Tusquets.

Damasio, A. (2010). Y el cerebro creó al hombre. Barcelona: Destino.

Debord, G. (1997). Rapport sur la constitution des situations. Paris: Mille et une nuits.

Deleuze, G. (2005). Derrames. Entre el capitalismo y la esquizofrenia. Buenos Aires: Cactus.

Deleuze, G. (1998). El Anti-Edipo. Barcelona: Paidós.

Deleuze, G. (1997). Mil mesetas. Madrid: Pre-Textos.

Descouturelle, F., Mignard, A., and Rodríguez, M., Guimard. (2012). L'Art nouveau du métro. Paris: La vie du Rail.

Fougeyrollas, P. (1971). La revolución freudiana. Madrid: Guadiana.

Freud, S. (1996-A). El Yo y el Ello. Madrid: Biblioteca Nueva.

Freud, S. (1996-B). La cabeza de Medusa. Madrid: Biblioteca Nueva.

Freud, S. (1996-C). Psicoanálisis y teoría de la libido. Madrid: Biblioteca Nueva.

Gay, P. (2010). Freud. Vida y legado de un precursor. Madrid: Paidós.

Han, Byung-Chul (2014). La agonía del Eros. Barcelona: Herder.

Jung. C.G. (2000). Freud y el psicoanálisis. Madrid: Trotta.

Khun, T.S. (1975). La estructura de las revoluciones cientificas. México: FCE.

Kristeva, J. (1998). Visions Capitales. París: Réunion des Musées Nationaux.

Lacan, J. (2006). Escritos. Barcelona: RBA.

Lacan, J. (2004). Seminario IV. La relación de objeto. Barcelona: Paidós.

Laurent, J. (2004). La imagen digital. De la tecnología a la estética. Buenos Aires: La Marca.

Leupin, A. (2000). Phallophanies. La chair et le sacré. París : Éditions du Regard.

Lyotard, J.F. (1981). Dispositivos pulsionales. Madrid: Fundamentos.

Lyotard, J. F. (2014). Discurso-Figura. Madrid: La Cebra.

Marcaccio, F., et al. (2014). Marcaccio Variants. Madrid: Polígrafa.

Marcuse, H. (1963). Eros y civilización. Paris: Minuit.

Martín Prada, J. (2012). Prácticas artísticas e internet en la época de las redes sociales. Madrid: Akal.

Marx, K. (1984). El Capital. El proceso de producción del capital. Madrid: Siglo XXI.

McLuhan M. y B. R. Powers. (2011). La aldea global. Madrid: Gedisa.

Pardo, J.L. (2011). El cuerpo sin órganos. Valencia: Pre-Textos.

Ostriker, J.P. y Mitton, S. (2014). El corazón de las tinieblas. Materia y energía oscuras: Los misterios del universo invisible. Barcelona: Pasado y Presente.

Repollés, J. (2011). Genealogías del arte contemporáneo. Madrid: Akal.

Roob, A. (2001). Alquimia \& mística. Colonia: Taschen.

Serres, M. (2014). Pulgarcita, Barcelona: Gedisa.

Zizek, S. (2006). Órganos sin cuerpo. Sobre Deleuze y consecuencias. Valencia:

Pre-Textos. 